REGARDS

SUR L'ECONOMIE ALLEMANDE

BULLETIN ECONOMIQUE DU CRAC

\section{Regards sur l'économie allemande}

Bulletin économique du CIRAC

$69 \mid 2004$

Varia

\title{
Fonction publique : négociations sur les statuts
}

\section{Marie-Hélène Pautrat}

\section{OpenEdition}

Journals

Édition électronique

URL : http://journals.openedition.org/rea/3403

DOI : 10.4000/rea.3403

ISBN : 978-2-8218-0834-8

ISSN : 1965-0787

Éditeur

CIRAC

Édition imprimée

Date de publication : 1 décembre 2004

Pagination : 35-36

ISSN : 1156-8992

Référence électronique

Marie-Hélène Pautrat, «Fonction publique : négociations sur les statuts », Regards sur l'économie allemande [En ligne], 69 | décembre 2004, mis en ligne le 27 janvier 2009, consulté le 15 septembre 2020. URL : http://journals.openedition.org/rea/3403

Ce document a été généré automatiquement le 15 septembre 2020

(C) CIRAC 


\title{
Fonction publique : négociations sur les statuts
}

\author{
Marie-Hélène Pautrat
}

\section{Vers une évolution des principes de la fonction publique}

1 Rémunération au mérite, révision des principes de progression des carrières, flexibilisation du temps de travail, etc. : les conditions d'emploi et de rémunération des 4,7 millions d'agents de la fonction publique allemande pourraient connaitre de profondes modifications. Deux grands chantiers de réforme sont en effet menés en parallèle: le premier vise à flexibiliser les conventions collectives qui servent de référence aux ouvriers et employés de la fonction publique. Ce dispositif contractuel, négocié par les syndicats et les employeurs publics (Bund, Länder et communes), fait l'objet de critiques récurrentes: il ne répondrait plus aux contraintes exogènes et endogènes de la fonction publique (concurrence, missions nouvelles et diversifiées, pyramide des âges, mobilité, etc.). En janvier 2003 (accord de Potsdam), les partenaires sociaux se sont donc engagés à le réformer. Le deuxième chantier s'attaque aux conditions de rémunération et de mobilité des fonctionnaires de carrière (Beamte) dont le statut et les rémunérations, réglementés par la loi, sont homogènes pour l'ensemble de la RFA, quel que soit l'employeur (Bund, Länder, communes) : des dispositions-cadre sont édictées au niveau fédéral et servent ainsi d'orientation aux législations des Länder. Dans les deux cas, une étape importante vient d'être franchie avec la présentation de propositions négociées.

Le périmètre de l'emploi public en Allemagne

\begin{tabular}{|l|l|l|l|l|}
\hline & Fonctionnaires & Employés & Ouvriers & Total \\
\hline \hline Bund $^{*}$ & 318200 & 97200 & 75700 & 491100 \\
\hline
\end{tabular}




\begin{tabular}{|l|l|l|l|l|}
\hline Länder & 1259200 & 776800 & 119200 & 2155300 \\
\hline Communes & 179700 & 952300 & 347900 & 1479900 \\
\hline Chemins de fer & 54700 & 600 & 2700 & 57900 \\
\hline Administration publique indirecte & 65000 & 474500 & 55600 & 595100 \\
\hline Total & 1876800 & 2301500 & 601100 & 4779400 \\
\hline
\end{tabular}

Source : Destatis, Deutschland 2004. *) Dont militaires (186 900); **) notamment administration du travail, Bundesbank, organismes de sécurité sociale, etc. Etat au 30.06.2003 (actualisation 02.08.2004).

\section{Länder : divergences sur le mode de réforme des accords collectifs}

2 Si les différents acteurs s'entendent sur le principe d'une évolution des conventions collectives des ouvriers et salariés du public, les employeurs se sont rapidement opposés sur la manière de procéder. Les Länder, réunis au sein de l'Association tarifaire des Länder (Tarifgemeinschaft deutscher Länder), se sont en effet retirés des discussions engagées avec le syndicat des services ver.di après avoir dénoncé en mars 2004 la convention collective qui fixe à 38,5 heures à l'ouest et à 40 heures à l'est la durée hebdomadaire de travail. Ils peuvent ainsi augmenter le temps de travail hebdomadaire pour les nouveaux contrats de travail, sans avoir à attendre l'issue des discussions. C'est le choix fait par la Bavière (42 heures hebdomadaires) ou encore la Rhénanie du NordWestphalie (41 heures).

\section{Communes : des propositions de réforme partagées avec ver.di}

3 Bien que divisées, les communes, qui emploient majoritairement des salariés contractuels, ont pour leur part opté pour la poursuite des discussions avec ver.di dans le but d'obtenir une réorganisation complète et concertée des principes régissant les conventions tarifaires : leur objectif prioritaire est de négocier un degré de flexibilité des accords suffisant pour qu'ils puissent s'adapter aux spécificités des différents secteurs sous leur responsabilité (personnel des collectivités locales, des régies municipales, hôpitaux, caisses d'épargne, etc.). Regroupées au sein de la Fédération des associations d'employeurs publics des communes (Vereinigung der kommunalen Arbeitgeberverbände), elles viennent ainsi de s'entendre avec ver.di sur un ensemble de mesures réformant les principes régissant les accords collectifs. Ces mesures pourraient servir de base de proposition aux prochaines négociations qui s'ouvriront en janvier 2005. 


\section{Accord possible sur le salaire au mérite}

4 Le consensus finalement trouvé implique un changement de paradigme avec notamment l'introduction du salaire au mérite. $2 \%$ de la masse salariale pourraient ainsi être répartis à partir de 2006 selon des critères de performance. Le financement de cette mesure serait garanti par une refonte des primes de Noël et de congés et la suppression de certaines indemnités supplémentaires liées à la situation de famille du salarié. Partant du constat que les communes confient toujours plus de tâches à des prestataires privés pratiquant des salaires inférieurs, l'accord prévoit également l'introduction d'un secteur à bas salaires, l'assouplissement des conditions de licenciement, de même que l'introduction de clauses d'ouverture autorisant les employeurs publics à déroger à la convention collective. Enfin, des mesures de flexibilisation du temps de travail sont envisagées, mais non pas un allongement général de la durée hebdomadaire, que récuse catégoriquement le syndicat ver.di. La portée d'un éventuel accord irait au-delà des 2,9 millions de salariés du public : près de 8 millions de salariés, dont les rémunérations suivent la grille de la fonction publique, pourraient être concernés.

\section{Bund : accord sur l'emploi des fonctionnaires ; une loi à l'étude}

Pour les 1,8 million de fonctionnaires stricto sensu (Beamte), les discussions menées quasi en parallèle entre le ministre de l'Intérieur Otto Schily, la confédération des fonctionnaires (DBB) et ver.di ont, de leur côté, abouti à la présentation début octobre d'un ensemble de propositions communes (Eckpunktepapier) qui pourraient donner lieu, dès le printemps prochain, à un projet de loi de réforme de l'emploi des fonctionnaires. Toute réforme passe en effet par la voie législative, voire par un amendement de la Loi fondamentale, si elle touche aux principes constitutionnels à l'origine du statut des fonctionnaires qui, rappelons-le, prêtent serment sur la Constitution. L'accord s'inscrit dans un contexte où plusieurs Länder revendiquent un renforcement de leur compétence législative pour les conditions de travail et de rémunération de leurs fonctionnaires (leur marge de manœuvre se limite aux allocations de Noël et de congés, voir REA 64/03).

\section{Révision des principes de rémunération et de carrière}

6 Le point-clé du projet porte sur une refonte des modalités de rémunération : la fonction et les tâches effectuées devraient prendre le pas sur la situation familiale et l'ancienneté. Le salaire serait dorénavant constitué d'une partie fixe et d'une part variable selon les performances, ouvrant la voie à une différenciation des salaires (variation dans un premier temps de 96 à $104 \%$ par rapport au salaire de base ; plus ou moins $10 \%$ à terme). Si globalement, l'homogénéité des conditions statutaires et de rémunération des fonctionnaires reste préservée, ce projet concède toutefois aux employeurs publics (et notamment aux Länder) une possibilité de différenciation des salaires de plus ou moins $5 \%$ afin de prendre en compte les contraintes spécifiques du marché du travail. D'autres éléments de réforme sont abordés, comme l'amélioration 
des conditions de mobilité vers le secteur privé et la constitution par l'Etat fédéral d'un fonds de réserve pour les pensions des futurs fonctionnaires fédéraux, juges et soldats. Cette position commune permet aux signataires de réformer sans toucher à l'architecture actuelle, c'est-à-dire en préservant la plus grande part des compétences du législateur fédéral. (MHP)

INDEX

Mots-clés : fonction publique, secteur public, réforme, emploi, statut, salaire, revenu, fonctionnaire 